\title{
A FÁBULA FLUSSERIANA E O FUTURO DA EDUCAÇÃ̃o ${ }^{1}$
}

\author{
LA FÁBULA FLUSSERIANA Y EL FUTURO DE LA EDUCACIÓN
}

THE FLUSSERIAN FABLE AND THE FUTURE OF EDUCATION

\author{
Luiz A. Calmon Nabuco LASTÓRIA
}

RESUMO: Este artigo parte de algumas concepções sustentadas por Vilém Flusser acerca das novas formas de pensamento emergentes a partir das novas tecnologias, bem como do desafio para a educação que daí se deriva - a "leitura" de imagens através dos conceitos -, e prossegue refletindo acerca do ponto cego presente em seu pensamento: a nova forma de exploração - aesthesis - própria ao capitalismo contemporâneo.

PALAVRAS-CHAVE: Educação. Tecnologia. Futuro.

RESUMEN: Este artículo parte de algunas concepciones sostenidas por Vilém Flusser acerca de las nuevas formas de pensamiento emergentes a partir de las nuevas tecnologías, así como del desafío para la educación que de ahí se deriva - la "lectura" de imágenes a través de los conceptos -, y prosigue reflejando acerca de del punto ciego presente en su pensamiento: la nueva forma de explotación - aesthesis - propia al capitalismo contemporáneo.

PALABRAS-CLAVES: Educación. Tecnología. Futuro.

ABSTRACT: This article is about some of Vilém Flusser's theoretical conceptions on the new forms of thinking arisen from modern technologies which encompass education's challenge: reading images through concepts. This article also reflects on the "blind spot" of Flusser's theory: the new exploration form - aesthesis - into the contemporary capitalism.

KEYWORDS: Education. Technology. Future

\section{Introdução}

\footnotetext{
${ }^{1}$ Este artigo foi extraído de parte de um conjunto de aulas de um curso intitulado TIC, Educação $e$ Cultura, que ministro atualmente no Programa de Estudos Pós-Graduados em Educação Escolar da Faculdade de Ciência e Letras da UNESP, Araraquara-SP. A principal motivação para redigi-lo se deveu a publicação do Decreto Presidencial $n^{\circ}$ 9.057, publicado em 25 de maio de 2017, que estabelece a ampliação da modalidade EaD para a educação brasileira em todos os seus níveis.

2 Universidade Estadual Paulista (Unesp), Araraquara - SP- Brasil. Prof. Dr. Livre Docente, do Departamento de Psicologia da Educação. E-mail: lacalmon@fclar.unesp.br
} 
Aqueles que já estão absolutamente convencidos acerca dos benefícios provenientes do acelerado desenvolvimento tecnológico que presenciamos, e que apostam nessa via como solução para os problemas candentes no âmbito educacional devem poupar-se de ler este artigo. Ele se endereça àqueles que, sabedores da irreversível presença das tecnologias de última geração nas diversas esferas da vida social, ainda creem que a autonomia, o bom senso e a justa medida devem ser os condutores primeiros de qualquer ato educativo.

Um ano antes de sua morte, em 1991, num seminário sobre o "Nomadismo" realizado na aldeia de Weiller, o filólogo e filósofo das novas mídias Vilém Flusser se referiu às três grandes catástrofes ${ }^{3}$ que se abateram sobre o homem, sendo que a terceira, dada a sua premência, ainda carece de nome. Na visão desse teórico tratar-se-ia de um fenômeno que expulsa, ao menos virtualmente, o sedentário de seu espaço doméstico, e o destitui de sua relação costumeira com as coisas. Este fenômeno nos impeliria a uma 'nova era de nomadismo', e cuja mobilidade virtual ocorreria em meio a 'não coisas' (informações, softwares e similares) Conforme as palavras do autor: "Sua casa torna-se inabitável, pois está perfurada pelo vento da informação". (FLUSSER, apud BAITELLO, p. 24, 2005). Nessa nova era de "nomadismo virtual" os deslocamentos devem ocorrer num espaço gerado por cifras e de dimensão nula. Nesse sentido sublinha o filólogo que 'sifr', em árabe, significa vazio; donde também se origina a palavra latina 'zero'.

Flusser argumenta ainda que se a escrita nascera primeiramente da inscrição, algo como uma "escavação do espírito, do ar, na terra" - barro, argila ou cerâmica -, e, sob a forma de imagens, para, somente depois tornar-se sobrescrita " $[. .$.$] ao depositar-se$ como pigmento sobre uma superfície", ela não poderia significar outra coisa senão os “cortes dilaceradores dos cadáveres de imagens" (FLUSSER, p. 25, 2005). E, nesse sentido, ao alinhamento dos elementos até então imagéticos correspondeu à invenção da escrita, e, com essa, a gênese daquilo que compreendemos ser hoje a nossa consciência histórica. No entanto, a terceira catástrofe, a pouco mencionada, implicaria, dessa vez, na passagem do pensamento expresso por linhas para o pensamento expresso por pontos que se organizam em planos imagéticos. "Zero" e "um", como se sabe, constituem a matriz de um novo tipo de pensamento, numérico por excelência, responsável pela

${ }^{3}$ A primeira catástrofe a que se refere o autor compreenderia a decida do homem para a savana tornandose um ser nômade (fahren/deslocar-se; erfahren/ficar sabendo); a segunda corresponderia ao seu processo de sedentarização (sitzen/estar sentado; besitzen/possuir). 
transposição virtual da realidade. Isto é: pela decomposição e síntese imagética dos homens e das coisas. Por intermédio do pensamento numérico opera-se a transformação de tudo em nada; fato esse que, para Flusser, corresponderia apenas a um tipo particular de decifração responsável por recobrar o significado original que a cifra mesma guarda desde sempre na sua essência: a nadificação do mundo e das coisas.

Logo, se não nos seria mais possível dar um passo sequer no sentido da abstração, pois os textos matemáticos representam o ápice da linguagem em termos abstratos, acredita Flusser que estaríamos "liberados" para projetar mundos e relações alternativas. Isto se torna possível na visão do autor porque na atual conversão da escrita em imagens, na passagem da linha para o plano, o pensamento não decresce. Ele apenas se transforma ao caminhar não mais da análise para a síntese, mas o inverso. Ao lermos textos escritos seguimos as linhas da esquerda para direita (ao menos nos casos das línguas flexionais) com o intuito de captar a mensagem neles codificada. Já diante de uma pintura ou de uma gravura, apreendemos a mensagem nelas codificada de um só lance, para, depois, nos determos em seus detalhes mais pormenorizadamente. Isto de modo a permitir novamente a diacronização daquilo que se encontra, a princípio, sincronizado pela imagem. Ao acompanharmos as linhas de um texto o fazemos para chegar ao entendimento de uma mensagem. No segundo caso ela já está dada desde o primeiro contato. Inversão essa que viria alterar fundamentalmente a nossa experiência com o tempo. Noutras palavras: as mensagens imagéticas comprimem o tempo necessário para que possamos decodificá-las; isto de modo a torná-lo, ao menos em princípio, mais denso. Nesse sentido, pensar por meio do contato com imagens não significa mais adequar os conceitos das coisas à extensão das linhas escritas. Aqui, observa Flusser, o ângulo de apreensão subjetiva joga o papel decisivo:

Códigos imagéticos (como filmes) dependem de pontos de vista predeterminados: são subjetivos. São baseados em convenções que não precisam ser aprendidas conscientemente: elas são inconscientes. Códigos conceituais (como alfabetos) independem de um ponto de vista predeterminado: são objetivos. São baseados em convenções que precisam ser aprendidas e aceitas conscientemente: são códigos conscientes. Portanto, a ficção imaginativa relaciona-se com os fatos de um modo subjetivo e inconsciente, e a ficção conceitual faz o mesmo de maneira objetiva e consciente (FLUSSER, 2007, p. 114).

Não obstante a potencial abertura em direção à criatividade proporcionada pelas novas linguagens icônicas, aspecto que confere plausibilidade ao argumento de Flusser segundo o qual não estaríamos nos deparando com um rebaixamento da atividade do 
pensamento, imagens de síntese podem ocasionar certa confusão entre a própria imagem e o seu referente. Tal ocorrência deve-se ao fato dessas imagens se constituírem em “ícones perfeitos", ou análogos "hiper-realistas" dos objetos que representam. Embora resultem de textos matemáticos, pois são em realidade metacódigos desse tipo de textos, as tecnoimagens ostentam um caráter pretensamente objetivo, não simbólico. Isso cria no observador uma espécie de confiança ilusória: "ele as olha [...]”, alerta-nos Flusser, “[...] como se fossem janelas, e não imagens resultantes de códigos simbólicos. O observador confia nas imagens técnicas tanto quanto confia em seus próprios olhos" (FLUSSER, p. 14, 2002).

Diferentemente das imagens tradicionais como as pinturas e os desenhos, que não ocultam o seu caráter de representação, as imagens tecnológicas o fazem na medida em que os aparelhos constroem um elo contínuo entre a imagem e seu significado. Fato que engendraria, conforme o autor, uma nova forma de magia ao nos proporcionar um "feitiço abstrato" que se deriva da "ritualização de programas", e cujo efeito encantatório parece ser o da produção de uma indistinção crescente entre as próprias imagens tecnológicas e os seus referentes na primeira realidade.

Mas seria errôneo supor que tal encantamento se perpetuaria indefinidamente, ou mesmo que estaríamos na iminência de um analfabetismo engendrado em escala de massa tendo em vista o declínio paulatino da codificação linear alfabética. Na visão do autor, a mutação cultural que presenciamos atualmente estaria nos desafiando a partir de uma tarefa ainda mais complexa e surpreendente. Isto na medida em que todo universo textual coexiste opondo resistência ao processo galopante das imagens tecnológicas. E, nesse sentido, o autor argumenta que diferentemente das imagens pré-tecnológicas que serviram para mediar a relação do homem com o mundo, as atuais tecnoimagens representam, antes de mais nada, textos. Tratar-se-ia, então, de aprendermos a decodificá-las enquanto modelos de conceitos, que, por sua vez, representam o mundo. O insucesso nessa urgente e imprescindível tarefa educacional redundaria num decréscimo abrupto de sentido num mundo que está se tornando velozmente codificado pelas novas linguagens tecnológicas. Hoje, mais do que outrora, os conceitos se tornaram imprescindíveis à formação do professor. Do contrário, como ensinar os nossos alunos a aprenderem por meio do contato com imagens? Disto decorre a falácia das novas retóricas pedagógicas que preconizam o "aprender a aprender" em detrimentos dos conteúdos. 
Ainda que Flusser não se atenha em considerações de ordem psicanalítica (ou mesmo psicológica), ao traçar o atual panorama da cultura sob o influxo das aceleradas transformações tecnológicas, ele assinala a proeminência da subjetividade no exercício de decodificação das informações imagéticas veiculadas pelas mídias digitais. Exercício esse que chamou de "ficção imaginativa", de caráter "inconsciente". Ele também nos adverte para a compressão do tempo, tal como experimentado pelos sujeitos agora colocados na posição de "nômades virtuais". Mas devemos nos interrogar acerca de que subjetividade se trata, uma vez que o próprio sujeito que habita a linguagem está se tornando um "estranho locatário"; isto na medida em que se encontra cada vez mais afeto pelos processos de metacodificação digital. Processos esses a partir dos quais toda produção sígnica, agora, direciona o sujeito para o objeto mesmo, e não mais para a cadeia significante, e, portanto, não mais para a mediação simbólica em nível da laboriosa atividade do pensamento ${ }^{4}$.

De outra parte, os possíveis destinos da educação na contemporaneidade, nos parece estar determinados por outro aspecto inerente ao fenômeno descrito por Flusser, porém não abordado por ele. Trata-se da "picada ótica" e da teleologia do choque imagético nas sociedades atuais: um processo já iniciado com advento da fotografia, e desenvolvido através do cinema em direção às tecnoimagens digitais.

Historicamente se pode reconhecer o impacto provocado pela fotografia - o particular tipo de choque que ela veio a produzir na percepção humana -, apenas quando traçamos um paralelo entre esse meio mecânico de produção de imagens e a sua antecessora: a heliogravura, criada em 1824 por Nicéphore Niépce. Ocorre que, por meio da heliogravura, o tempo despendido para que o sol desenhasse de modo simultâneo a imagem sobre a pedra recoberta com substâncias químicas sensíveis à luz continha já o efeito de choque que viria a ser provocado pela fotografia, mas apenas em seu estado latente. Isto na medida em que esse tempo era ainda demasiado longo para que a simultaneidade da figura impactasse a percepção humana de modo repentino. $\mathrm{O}$ passo derradeiro foi dado por Daguerre, em 1839. Os então chamados "daguerriótipos" consistiam em placas de prata iodada sobre as quais o vapor de mercúrio fazia aparecer as primeiras imagens fotográficas. A partir de então as imagens puderam ser

\footnotetext{
${ }^{4}$ A questão da compressão do tempo produz uma serie de sintomas que podem ser tratados nos limites desse artigo. Sobre certas consequências em nível do sujeito advindas das formas de pensamento abreviado, tal como requerido por uma educação realizada através do contato com imagens instantâneas obedecendo a fins pragmáticos, remeto o leitor para o texto "Tecnoimagem e sujeito". In: Revista Artefilosofia. $n^{\circ}$ 8. Ouro Preto: Ed. UFOP, 2010.
} 
transladadas das espessas e pesadas placas prateadas para o papel leve e fino. Assim pôde-se baratear o custo de produção das imagens fotográficas tornando-as ao mesmo tempo altamente reprodutíveis.

O protótipo da câmera escura, como se sabe, foi o olho humano. Ela se constitui numa retina artificial, que, como num piscar de olhos, fixa com perfeição uma imagem - análoga perfeita do real - de modo a impactar, com o horror da morte, os seus primeiros admiradores. Christoph Türcke ${ }^{5}$ destacou o quão ativas estas inocentes imagens se mostraram desde o início: “[...] elas destacam do continuo de incontáveis instantes um único e o paralisam" (TÜRCKE, p. 176, 2010a). Desse modo irradiam insidiosamente o seu modo de ver o que se passou. Mas é preciso ter presente que as fotografias mesmas nunca perdem o seu caráter de "cópia performática", tal como também o foram (e ainda o são) os ancestrais ritos de oferendas em que se encenam a presença de ausências. Por mais perfeita que uma imagem possa parecer, ela não passa de uma presentificação artificial de algo já ocorrido.

Türcke, porém, enfatiza o fato de que na captura imagética de um instante qualquer, a criatura supera o criador ao menos num aspecto: enquanto o olho humano consegue concentrar a atenção num objeto apenas por um tempo bastante limitado, captando a sua imagem de modo nítido no ponto central da retina (fóvea), a câmera se mostra incansável, bem como a sua nitidez homogênea em todas as regiões da extensão fotográfica. Essa superioridade, contudo, cobra um alto preço: fotografar equivale a paralisar, matar. O que o grito de pavor intenciona fazer mediante a voz, a paralisação intenciona mediante a imagem. Em tempos arcaicos tratou-se da tentativa de afastar o pavoroso, de destituí-lo de sua potência de ação (como nas pinturas rupestres). No entanto, somente nas condições culturais modernas o positivismo aplicado à ótica (com sua neutralidade e objetividade) superou em definitivo as formas artesanais plásticas de representação pré-modernas.

${ }^{5}$ Christoph Türcke é Professor de Filosofia, aposentado na Hocheschule für Grafik und Buchkunst, em Leipzig. Devido à forte presença da teoria psicanalítica no conjunto de sua obra, e, consequentemente, ao tratamento despendido pelo filósofo ao pensamento freudiano, C. Türcke foi homenageado com o prêmio Sigmund-Freud-Kulturpreis, em 2009, concedido por duas instituições psicanalíticas alemãs: Die Deutsche Psychoanalytische Vereinigung (DPV) e Deutsche Psychoanalytische Gesellschaft (DPG). Os livros Filosofia do Sonho, Sociedade Excitada: Filosofia da Sensação, ambos publicados no Brasil em 2010 pelas editoras da Universidade de Ijuí e da Unicamp, respectivamente, ao lado de Do Sinal de Caim ao Código Genético: Teoria crítica da escritura, ainda não publicado no país, compõem uma trilogia mediante a qual o autor disseca a sociedade midiática contemporânea revigorando o pensamento crítico iniciado pelos filósofos da primeira geração do Instituto de Pesquisa Social de Frankfurt. 
A câmera dispara. Clicar equivale a disparar uma arma, e, focar, equivale a acertar o alvo desejado. Benjamin (1993) havia definido a aura de uma coisa como "[...] a aparição única de uma distância, por mais próxima que esteja". E, nesse caso, a fotografia implica na destituição da singularidade do original, argumentou Benjamin. Do negativo sempre se pode fazer inúmeras cópias! Mas, de outra parte, a fotografia implica, igualmente, numa inversão da aura se considerada sob o ângulo do objeto (e não da imagem), observou Türcke: “[...] aparição de uma proximidade única, por mais distante que esteja" (TÜRCKE, p. 177, 2010a). Ocorre que, ao acertar o seu alvo, o fotógrafo, tal qual o caçador, não carregaria consigo apenas a "pele aurática" da sua caça? E, não corresponde a essa mesma pele sem vida uma simplificação industrial gigantesca e propícia à divulgação massiva dos concentrados culturais com finalidades educacionais no presente?

Vale lembrar que a vulgarização possibilitada pela reprodução mecânica, e agora digital da imagem em nada alterou a estrutura fundamental que também animava os antigos rituais mágicos. Isto é: fazer com que algo que atemoriza perca o seu poder atemorizador natural. Dos bisões pintados nas cavernas de Lascaux às atuais películas reveladas, ou resolvidas em pixels, a estrutura que despe o perigo paralisando a coisa se manteve praticamente a mesma. Porém, após o advento da reprodução mecânica da imagem uma inversão se sucedeu: o banimento se inverteu e passou a insuflar vida nova ao que foi dominado. As imagens uma vez pacificadas passaram, aos poucos, a servir de alimento para a fantasia humana. Nas palavras de Türcke: "A paralisação se torna uma nova vivificação daquilo que fora paralisado. É certo que o combate ao pavor se articula originalmente como desejo de matar. Mas, à medida que o pavor empalidece, manifestase nesse desejo de matar o desejo de viver" (TÜRCKE, p. 180, 2010a). Ocorre que o estado de paz que brota do perigo pacificado pelo engenho da técnica, não deixa de apontar para a utopia: aquele estado de felicidade plena sob a forma de um "agora estático". No entanto, não se deve perder de vista que a sua concretização hodierna pela "cultura digital", apenas se faz passar pela utopia já realizada devido ao estágio do desenvolvimento tecnológico por nós alcançado.

Portar ou postar um instante paralisado é obra da técnica; ainda que o preço seja o da própria vida na medida em que com o emprego da técnica se fabrica apenas o sucedâneo. De outra parte, nessa fabricação o instante real, como que num passe de mágica, figura salvo da torrente do tempo. No entanto, o imperativo "façam-se imagens", desencadeado no compasso da máquina a vapor desde a aurora da nova 
ordem burguesa, impulsionou adicionalmente nada menos que a industrialização de toda e qualquer manifestação cultural humana. $\mathrm{O}$ ato inaugural dessa indústria, ao menos no que diz respeito ao seu vínculo congênito com a reprodução mercadológicas das imagens, pode ser localizado no ato de venda dos daguerreótipos ao governo Frances por parte de Daguerre. Salvar é obra de deus, e selecionar é obra do mercado, lembranos Türcke. Assim, a fotografia aliada à propaganda encontra-se no ponto de confluência da metafísica com o mercado capitalista. A esse respeito é ilustrativa a colocação do autor: "É claro que ser aceito pela retina artificial pode ser uma eleição tão miserável quanto a de ser aceito pelo mercado. E, no entanto, isso significa a salvação daquela banalidade e insignificância pelas quais tudo que não se torna imagem está ameaçado de ser acometido" (TÜRCKE, p. 184, 2010a).

O impacto da chamada "cultura digital" nos dias atuais determina que toda existência seja sorvida pelo cânone da imagem até que esta venha a se constituir na chancela daquela. Não existir em imagem significa hoje quase não possuir uma identidade, não existir socialmente. Tudo se passa como se somente a tecnologia fosse capaz de chancelar tanto o status da nossa singularidade pessoal, quanto o status de excepcionalidade dos momentos por nós vividos. Nisso reside a transferência da curiosidade relativa ao conteúdo vivo para a forma que o realiza. Não possuir uma homepage na internet equivale, atualmente, a quase não existir, na medida em que a virtualidade se nos impõe recobrindo, em quase toda a sua extensão, as formas tradicionais de existência social. E, nesse sentido, pode-se afirmar que somente pela forma tecnológica vigente a nossa existência pode ser "salva", porque destacada mediante seleção. Os "gritos óticos mudos", assim Türcke denomina as fotografias, realizam sob a forma imagética o mesmo que os sonoros gritos dos feirantes de outrora: chamar a atenção dos transeuntes para as suas próprias mercadorias dispostas ao público. Daí a conclusão de que imagem, propaganda e mercado se entrelaçam de modo endêmico. Pois, se o fetiche da mercadoria abarca a sua aparência social, essa engloba o seu modo estético de produção/apresentação. E é a imagem, que, por sua vez, constitui o segredo que dota toda mercadoria de uma aparência sensível.

Ocorre que a profanação do sagrado, tal como fora prognosticado pelo Manifesto Comunista, escrito por Marx e Engels (2015), significou também uma sacralização implícita do próprio mercado. Crer no mercado é ainda crer de algum modo, mesmo que se saiba de antemão que o mercado é constituído por um conjunto de relação de trocas laicas. 
Daí a singular situação oscilante para a qual transporta a magia do instante paralisado fotograficamente. Obstinar-se na ideia de que ele irradia a sensação do sagrado é absurdo; mas dizer que ele não o faz de modo algum também não é correto. É necessário buscar refúgio nas metáforas, quando se quer compreender essa oscilação entre ser e não ser (TÜRCKE, p. 193-194, 2010a).

Marx, como se sabe, captou o caráter sacro do mercado ao sugerir o poder fetichista da mercadoria. Não obstante, na visada de Türcke, faltou-lhe extrair as últimas consequências de sua própria análise. Aqui, a câmera escura deve encerrar a materialidade da metáfora procurada: um aparelho, que, tal como uma caverna é capaz de ecoar o som, é capaz de enfeitiçar a sombra e multiplicá-la freneticamente até que ela comece a adquirir vida própria. Assim, o sucedâneo irá tomando o lugar da própria coisa.

O mecanismo por meio do qual as imagens adquirem vida própria e se constituem em novos padrões normativos conformará paulatinamente uma verdadeira artilharia de projéteis. E, assim como o olho se volta espontaneamente para onde a luz pisca, explica-nos Türcke, e:

só por um breve esforço pode ser impedido de fazê-lo, ele também não pode, a longo prazo, ser impedido de olhar para um ponto do qual um enrijecimento relâmpago dispara em sua direção como um relâmpago enrijecido. Assim, o imperativo categórico se faz notar com a incondicionalidade de um choque traumático, apenas que nesse caso se trata de um choque dissolvido em uma infinidade de minúsculas picadas de agulhas óticas, de uma incondicionalidade multiplicada, quase não mais apreensível, em outras palavras, trata-se do choque traumático na condição de sombra de si mesmo volatilizado e refinado até se tornar irreconhecível (TÜRCKE, 2010, p. 195).

Esse processo de saturação do choque traumático iniciado com a fotografia se encontra potencializado a partir da chamada revolução microeletrônica. Nos dias atuais o choque imagético altamente pulverizado e refinado é que cadencia o ritmo compulsivo do modo de produção capitalista para a extração do valor em escala ampliada. Se isso é verdadeiro, então o conceito de exploração também deve ser por nós considerado e analisado sob as lentes microscópicas na era da microeletrônica. Somente nesta era o mercado se expandiu a tal ponto de modo a conformar a sociedade global como sociedade de mercado universal. E sob a atual ordem burguesa, o mercado totalmente profanado se tornou a instância de socialização por excelência ao engolfar a família e a escola. 
A partir de então:

No momento em que o mercado começa a se tornar absoluto, seu mecanismo profano de seleção se eleva a uma instância de eleição e rejeição, do destino, da produção de sentido. Todos sabem o quanto esse sentido é miserável, mas todos têm de percebê-lo como um sentido elementar por meio do qual sua vida material é determinada até nas menores coisas (TÜRCKE, 2010a, p. 214-215).

Doravante toda existência individual não será mais possível a não ser pela mediação do mercado. E, nas condições do mercado absoluto verifica-se o retorno da percepção humana em direção aquilo que o autor denomina por "sensação absoluta". Somente que, desta vez, a sensação absoluta engendra-se gradativamente mediante a intensificação paulatina de infinitos choques audiovisuais concorrentes; isso de modo a conformar uma estrutura cultural compulsiva e viciadora, e não mais pelo descomunal pavor que teria acometido os nossos ancestrais quando do alvorecer da consciência humana em presença dos fenômenos naturais.

O choque do instante congelado provocado pela fotografia sobre o sensório do observador guarda uma peculiaridade: nele, tal qual uma mônada, a intuição da sensação constitui o elo que interliga a pré-história e o presente da sensação:

O ponto no qual o seu caráter arcaico da epifania ainda cintila, e o seu já de alta tecnologia. Aqui ambos se iluminam mutuamente. Mas o ponto de sua sobreposição recíproca é o ponto no qual o caráter de fetiche da mercadoria se torna patente - talvez o único a partir do qual a sua extensão se deixa mensurar (TÜRCKE, 2010a, p. 228).

O fato de que a fotografia serviu de base para o cinema de modo a fincar o hábito perceptivo do olho de acompanhar imagens em movimento, em nada altera o caráter de mônada inerente ao choque fotográfico. Aliás, o que se verifica na tela nada mais é do que o efeito da ilusão de ótica. Noutras palavras, o movimento aparente criado a partir da passagem de um mínimo de 24 fotogramas estáticos por segundo, diante da retina humana. Por se constituir em continuidade no tempo, e não do tempo, o filme só pode ser produzido a partir da montagem. E, não pode haver montagem sem cortes. Assim, cada corte constituirá a prova empírica que desmente a continuidade do filme. E mais, nele: “O solavanco da imagem enrijecida retorna e ganha, pelo contraste no qual ele trabalha para continuidade simulada, uma intensidade que ele jamais tivera na fotografia. O ponto de corte no filme potencializa o choque imagético da fotografia" 
(TÜRCKE, p. 230, 2010a). Assim o ponto de corte do filme nada mais é do que o retorno do solavanco inerente ao choque da fotografia, e que agora se intensifica.

Ocorre que os choques imagéticos iniciados com a fotografia, e postos em movimento pelo cinema promovem certa distração, somente que a partir do confisco de nossa capacidade de atenção. Doravante, a capacidade de concentração das massas durante a exibição de um filme dirigir-se-á inteiramente para um único ponto a partir do qual sua atenção será triturada a partir de incontáveis repetições, de modo a converter-se em "distração". "O meio de concentração é, propriamente, o meio de decomposição" (TÜRCKE, p. 266, 2010a), dirá Türcke. Desse modo inicia-se o equivalente em nível da percepção humana daquele fenômeno que Marx chamou de subsunção real do trabalho ao capital. Ora, do mesmo modo que somente aquela "parte" do trabalhador correspondente a sua força de trabalho é vendida ao capitalista para ser explorada sob a batuta da maquinaria, processo no qual se separam claramente o tempo de trabalho do tempo livre; com o cinema, tal como ilustrado por Chaplin, a percepção iniciou o seu treino para o trabalho nas condições daquele tempo que restara do próprio trabalho e fora considerado como supostamente livre.

Por essa via o organismo irá se viciar ao receber incontáveis e irresistíveis picadas óticas diariamente com o intuito de, tal como uma vacina, imunizá-lo contra o efeito triturador da atenção, e, concomitantemente, extrair algum prazer dos seus impulsos.

E isso da mesma forma como o organismo, que se adapta ao consumo de doses de nicotina, álcool e cocaína, também relaxa ao consumi-las. Por meio de tal relaxamento, pôde-se demonstrar o que se exigiu do sistema nervoso, que não suportaria mais, em estado desperto, uma quantidade menor de excitação e de tensão (TÜRCKE, 2010a, p. 278).

Logo, a subsunção real do trabalho pelo capital, captada em termos dos minúsculos choques audiovisuais, nos revela em sua face estética, nada menos que a dinâmica viciadora inerente à exploração sistemática levada a cabo pelo capitalismo atual. Nesse processo "choque" e "trabalho" coincidem. Daí o sintomas em voga: workholics, depressões e TDAHs ${ }^{6}$, dentre outros. As "imagens normas" expressam inequivocamente os imperativos econômicos presentes num ethos que, em grande medida, já fora reconfigurado pela alta tecnologia digital. Através da estetização da vida quotidiana, sobretudo das relações de trabalho e de educação, se realiza tanto a

${ }^{6}$ A esse respeito C. Türcke desdobra o seu argumento noutra importante obra intitulada Filosofia do sonho (2010b). 
expropriação da atenção, quanto a exploração econômica aliado àquilo que Türcke denominou a partir de Hegel como sendo o "retorno ao fundamento". Isto é:

Quanto menos a força muscular foi aplicada às máquinas colossais, quanto mais as pontas dos dedos e os movimentos oculares foram motora e refinadamente alinhavados a aparelhos microeletrônicos, mais se destaca para qual direção a transformação da exploração aponta: para a exploração da concentração (TÜRCKE, 2010a, p. 274).

E isso significa nada menos que, doravante, a concentração que antes fora "ligada" ao longo de incontáveis milênios, de modo a ensejar as nossas formas perceptuais de recepção e expressão, representações e conceitos, enfim, os assim chamados "processos mentais superiores", inicia uma marcha-ré. E, a partir de então, a subsunção sistemática dos processos perceptuais passou a cravar os dentes na vítima, e, tal qual um vampiro, começou a sugar sua capacidade cerebral nervosa em termos de abstração. Daí uma das principais consequências da tão propalada crise do código escrito: a baixa capacidade de abstração hoje verificada em massas estudantis inteiras em todos os níveis do sistema educacional.

Aristóteles (2006) definira as imagens mentais (phantasmata) em seu De Anima como algo imaterial, porém decorrentes da percepção (aisthemata). Trata-se, portanto, de impressões provenientes dos nossos sentidos que se "desrealizam" sob a forma de imagens arquitetadas graças aos registros mnemônicos. Uma tal materialidade volátil constitui nada menos que a base das nossas abstrações conceituais. Qualquer objetivação humana, seja ela um pintura, partitura ou pensamento conceitual tem de passar necessariamente pela "forma" antes de saltar da subjetividade para a tela, pauta ou papel. E essa forma nunca pode se livrar de todo da imagem antes configurada mentalmente (etapa noética do processo de objetivação). Por isso se pode afirmar que:

As abstrações mentais não poderiam conservar-se, caso não fossem forradas e revestidas dessa massa de excitação imagética. Mesmo o mais abstrato, a trama mais puramente 'original', deve nascer do mundo como um todo e não pode ser pensado sem ser associado com a representação de sua luz original, que ele irradia; sem a representação de sua fonte original, que ele deságua (TÜRCKE, 2010a, p. 283).

Com o advento do registro fotográfico de imagens, e, posteriormente, com a filmadora, porém, o olho humano as percebe como uma verdadeira metralhadora de 
projeteis disparados contra o sistema nervoso "[...] como se elas desejassem vingar-se do que ele lhes fizera", acrescenta o autor: a violência da abstração textual responsável por engendrar a sensualidade de alta resolução das tecnoimagens contra-ataca o sistema nervoso minando a sua capacidade de abstração. Às fugazes imagens internas sobrepõem-se as potentes imagens externas empalidecendo-as e obstruindo paulatinamente a sua observação. De sorte que "[...] as imagens externas formam as imagens internas, [...]. E, os conceitos - o produto máximo da abstração, aquilo que é mais destituído de imagem no sistema nervoso - se transforma naquilo que mais necessita de imagem" (TÜRCKE, 2010a, p. 284). E:

\begin{abstract}
Quando o fundo imagético interior, do qual eles se elevam e se nutrem, é destituído, então eles se tornam algo sem chão, sem referência, frios, literalmente 'absolutos', tal como eles jamais foram em nenhum sistema filosófico anterior; tal como se eles fossem apenas a escrita invertida de cada uma das fórmulas matemáticas, as quais transformaram as imagens externas em abstrações reais. Eles não mais se conservam, pois voam ao encontro da luz. Aquilo que surrupia o apoio se transforma no próprio, não diferente do que fazem a aguardente e a heroína (TÜRCKE, 2010a, p. 284).
\end{abstract}

Uma vez desencadeado, esse processo conduz a contínua intensificação das minúsculas picadas óticas, bem como de toda imensa gama de choques promovidos pela artilharia tecnológica multisensorial, em direção à sensação absoluta. Revela-se com isso não apenas a estrutura viciante inerente ao desenvolvimento da sociedade de mercado capitalista, cuja exploração se efetiva em nível da percepção estética, como também a estrutura neurofisiológica regressiva do sensório humano em direção ao seu próprio fundamento: o susto traumático cuja carga energética outrora se fez escoar pelo sistema nervoso ensejando os cultos sacrificais e a própria cultura.

A fábula flusseriana segundo a qual a partir do advento de uma "nova era de nomadismo", a qual seria responsável por tornar a nossa própria casa inabitável, uma vez que ela se encontra agora "perfurada pelo vento da informação", nós estaríamos liberados para projetar mundos e relações alternativas, simplesmente desconhece tais consequências.

\title{
REFERÊNCIAS
}

ARISTOTELES. De anima. São Paulo: editora 34, 2006. 
BENJAMIN, W. A obra de arte na era da sua reprodutibilidade técnica. In: Obras escolhidas. Tomo I. São Paulo: Brasiliense, 1993.

FLUSSER, V. Filosofia da caixa preta: ensaios para uma futura filosofia da fotografia. Rio de Janeiro: Relume Dumara, 2002.

FLUSSER, V. Língua e realidade. São Paulo: Annablume, 2005.

FLUSSER, V. O mundo codificado: por uma filosofia do design e da comunicação. São Paulo: Cosac Naify, 2007.

LASTÓRIA, L. A. C. N. Tecno-imagem e sujeito. Revista Artefilosofia, n. 8. Ouro Preto: Ed. UFOP, 2010.

MARX, K.; ENGELS, F. Manifesto do partido comunista. São Paulo: Edipro, 2015.

TÜRCKE, C. Sociedade excitada. Campinas: Ed. Unicamp, 2010a.

TÜRCKE, C. Filosofia do sonho. Ijuí: Ed. Unijuí, 2010b.

\section{Como referenciar este artigo}

LASTÓRIA, Luiz A. Calmon Nabuco. A fábula flusseriana e o futuro da educação. Revista on line de Política e Gestão Educacional, Araraquara, v. 21, n. esp. 1, p. 591604, out./2017. Disponível em: <http://dx.doi.org/10.22633/rpge.v21.n.esp1.out.2017.10424>. E-ISSN:1519-9029..

Submetido em: 10/06/2017

Aceite em: 18/07/2017 